\title{
The ASSessment of WaVelet Transform Parameters REGARDING ITS USE IN 3D SURFACE FILTERING
}

\author{
Damian Gogolewski, Włodzimierz Makieła, Krzysztof Stępień, \\ Paweł Zmarzły \& Mateusz Wrzochal
}
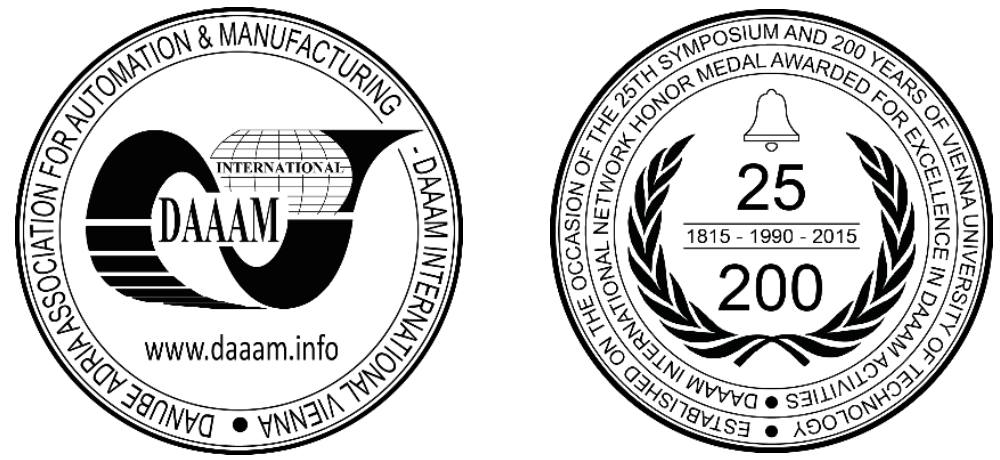

This Publication has to be referred as: Gogolewski, D[amian]; Wlodzimierz, M[akiela]; Stepien, K[rzysztof]; Zmarzly, P[awel] \& Wrzochal, M[ateusz] (2018). The Assessment of Wavelet Transform Parameters Regarding Its Use in 3D Surface Filtering, Proceedings of the 29th DAAAM International Symposium, pp.1191-1196, B. Katalinic (Ed.), Published by DAAAM International, ISBN 978-3-902734-20-4, ISSN 1726-9679, Vienna, Austria DOI: $10.2507 / 29$ th.daaam.proceedings.172

\begin{abstract}
This paper assesses the impact of certain parameters of a wavelet transform on the 3D surface decomposition process regarding transform's application to divide components of surface texture. The tests focused on determination of the relation between horizontal sampling density, type of mother wavelet and level of wavelet decomposition. The analysis included samples manufactured with use of the SLM additive technology. Sample surface measurements were performed by Talysurf CCI optical profilometer, applying specified sampling density depending on an objective type being used. The obtained 3D profiles were filtered with use of selected mother wavelets. The paper also covers the analysis of the impact of a mother wavelet type on values of selected 3D surface roughness parameters. The obtained results were subject to statistical analysis.
\end{abstract}

Keywords: wavelet analysis; filtration; surface roughness; additive technology; horizontal sampling density

\section{Introduction}

The geometric structure of surfaces in the elements shaped during the manufacturing process contains various periodical and non-periodical types of irregularities including form, waviness and roughness of surfaces. Certain types of irregularities are distinguished depending on a ratio between average width of irregularities to its average height, while assurance of appropriate quality of a surface layer is a key issue having the impact on correct operation of machine parts.

In industrial practice a key problem is the assessment of roughness of produced machine parts. Surface roughness has the significant impact on, inter alia, quality of co-operation of associated machine elements, fatigue limit, wear and corrosion resistance, contact force resistance, flow resistance and joint tightness. There are many methods dividing components of irregularities in the geometric surface texture. Among those generally and widely known there are methods using appropriate measuring head with specified tip radius, acting as a mechanical-geometrical filter (contact profilometers) or using analogue or digital filters. Nevertheless, the most often used method dividing components of irregularities in the surface texture is digital filtering [1]. 
Such analysis includes application of filters with specific cut-off length, depending on a type of analyzed surface irregularities. The measurement signal during the analysis is filtered by two complementary filters, the high-pass filter and the low-pass filter. The high-pass filter extinguishes components arising from form and surface waviness. After such filtering the received signal becomes a surface roughness signal. The similar role is played by the low-pass filter that extinguishes components related to a roughness signal, leaving low-frequency components. One of the most often used filters is the band Gaussian filter defined in the PN-EN ISO 1156 standard. Nonetheless, these methods refer mostly to analysis of surface profiles, however versions of selected procedures can be used to execute the filtering process for a 3D surface texture [2],[3].

Development of science and techniques determines capabilities of designing algorithms currently used in the analysis of geometrical product specification signals, as well as development of new analytical methods for measurement signals. Wavelet analysis, developed at the turn of the $20^{\text {th }}$ and the $21^{\text {st }}$ century, is a good example of this tendency.

During the analysis with use of a wavelet transform a signal, analogically to the Gaussian filter, is filtered by using two filters, the high-pass and the low-pass filters. Thus, on subsequent levels of decomposition the input signal becomes smoother. The received approximate signal corresponds to low-frequency information, while signal's details contain its high frequency information (surface roughness). While analyzing current state-of-art, we can noted many application of wavelet functions in 3D surface analysis [4],[5]. In their study [6] Jiang and Blunt used complex wavelets in order to detect minor, though crucial surface properties. Chen et al. [7] analyzed the fractal dimension and performed the analysis of three-dimensional signals of a surface texture.

Dutta et al. [8] analyzed the surface obtained as a result of the turning process with use of a two-dimensional wavelet transform in order to investigate tool wear. Two-dimensional mother wavelets were also used by Josso et al [9] and Lingadurai and Shunmugam in their study [10] in order to characterize the analyzed surface and divide it into components. According to [10], using a wavelet transform to divide a measured surface into components allow to obtain better filtration results due to more sharper transmission characteristic of the filter, when compared it to the analysis using a Gaussian filter.

Research related to the multi-scale analysis of a two-dimensional wavelet transform was conducted by Zahouani et al. in their paper [11], while Yang et al. [12] analyzed possibilities to use wavelet functions in the image analysis for surfaces measured under various light conditions. The analysis of surface texture signals with use of a two-dimensional wavelet transform was made, inter alia, in [13],[14],[15], however studies lack detailed guidelines specifying certain parameters of wavelet transformation. Adaptation of a wavelet transform regarding its application in determining surface roughness signals requires both the level of wavelet decomposition for the profile with specified horizontal sampling density and type of the mother wavelet used in the analysis [16].

Thus, it was purposeful to investigate selected parameters of a two-dimensional wavelet transform regarding its application in the analysis of surface topography. The analysis was performed using samples produced by the SLM (Selective Laser Melting) additive technology.

\section{Test methodology}

Development of unconventional manufacturing technologies determines their growing application in various fields of industry, so the analysis of the surface texture in ready-to-use elements is becoming a key issue. This analysis was conducted using surfaces of samples produced at specified process parameters, considering the phenomenon of anisotropy occurring in elements produced with use of all additive technologies. In this regard the following features were specified: type of material (steel 316L), layer thickness $(25 \mu \mathrm{m})$ and placement of the model on the machine platform. The angles of model inclination to the platform were determined on three level: $0^{\circ}, 45^{\circ}$ and $90^{\circ}$.

Using the optical Talysurf CCI profilometer, sample surfaces were measured for specified density of measuring points. It was determined that $0.841 \mathrm{~mm}$ x $0.841 \mathrm{~mm}$ surfaces should be analyzed. The measurement was performed using three available objectives: $\mathrm{x} 10, \mathrm{x} 20$ and $\mathrm{x} 50$, so for certain objectives different size of the matrix of coefficient defining the surfaces being analyzed. The table 1 shows sizes of coefficient matrices, depending on an objective used for measurement, while it was decided that all 3D profiles should have the same size.

\begin{tabular}{|c|c|}
\hline Objective magnification & Matrix size (number of measuring points) \\
\hline x10 & $525 \times 525$ \\
\hline x20 & $1024 \times 1024$ \\
\hline x50 & $2562 \times 2562$ \\
\hline
\end{tabular}

Table 1. Sizes of matrices of surface-defining coefficients, depending on an objective used for measurement.

The obtained surface profiles were analyzed with use of a Gaussian filter with cut-off length $\lambda c=0.8 \mathrm{~mm}$. The roughness surface occurring as a result of filtering were compared to the surface created as a result of application of a discrete wavelet transform. Particular surface profiles were analyzed with use of selected mother wavelets. 
On the basis of performed initial tests the following mother wavelets were selected for analysis: $d b 15$, $d b 20$, coif4, coif5, sym8, sym10, bior3.9, bior6.8. For each sample at subsequent level of decomposition the Pearson correlation coefficient was determined for the received 3D profile after conducting wavelet filtering and filtering with use of a Gaussian filter. It was assumed that the roughness surface occurring as a result of application of the selected wavelet functions shall be defined as the sum of details obtained for a given, specified analysis level. In order to perform the more complex analysis the selected parameters of surface roughness were also compared. The following 3D parameters were selected: $S a, S q, S k u$. The figure 1 shows the examples of surface images obtained as a result of measurements using the x20 objective magnification.
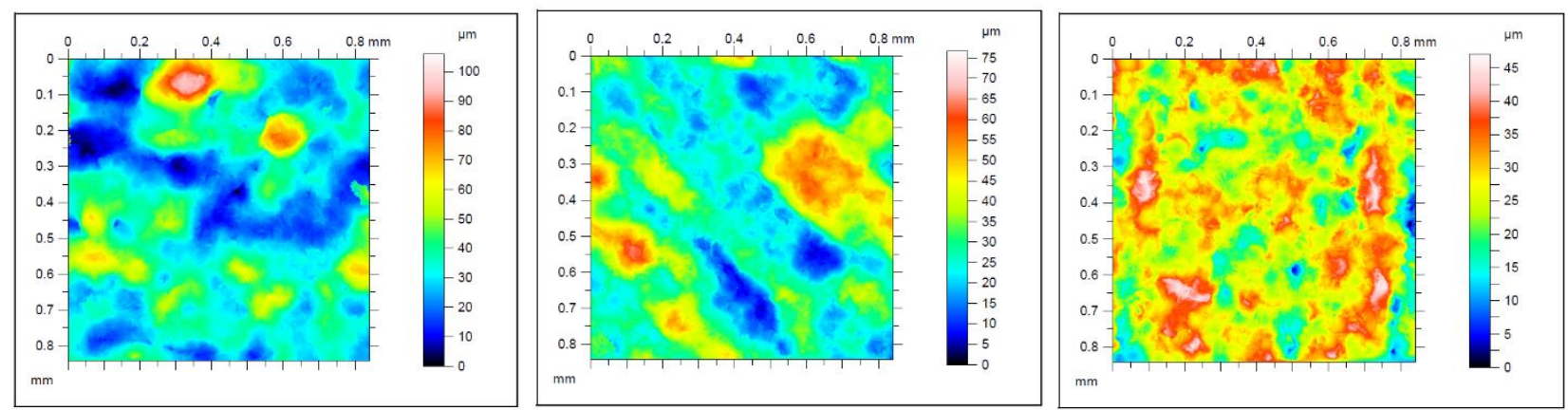

Fig. 1. Surface image obtained as a result of measurements using the $\mathrm{x} 20$ objective magnification at angle of (a) $0^{\circ}$; (b) $45^{\circ}$; (c) $90^{\circ}$.

\section{Research results}

The first stage was to determine the correlation coefficient value between signals in order to identify the decomposition level, to which the filtration should be performed. At the defined analysis level it was noted significant similarity of the received signal after application wavelet analysis and Gaussian filtration. The figure 2 shows the research results for the surfaces manufactured at the angle of $0^{\circ}$, while the figure $2 \mathrm{a}$ shows the results for the $\mathrm{x} 10$ objective magnification, $2 \mathrm{~b}$ for $\mathrm{x} 20$ and $2 \mathrm{c}$ for $\mathrm{x} 50$. Analogical calculations were performed for the samples manufactured at two other angles of model inclination to the machine platform. The figure 3 refers to the samples manufactured at the angle of $45^{\circ}$, while the figure 4 to the samples manufactured at the angle of $90^{\circ}$.
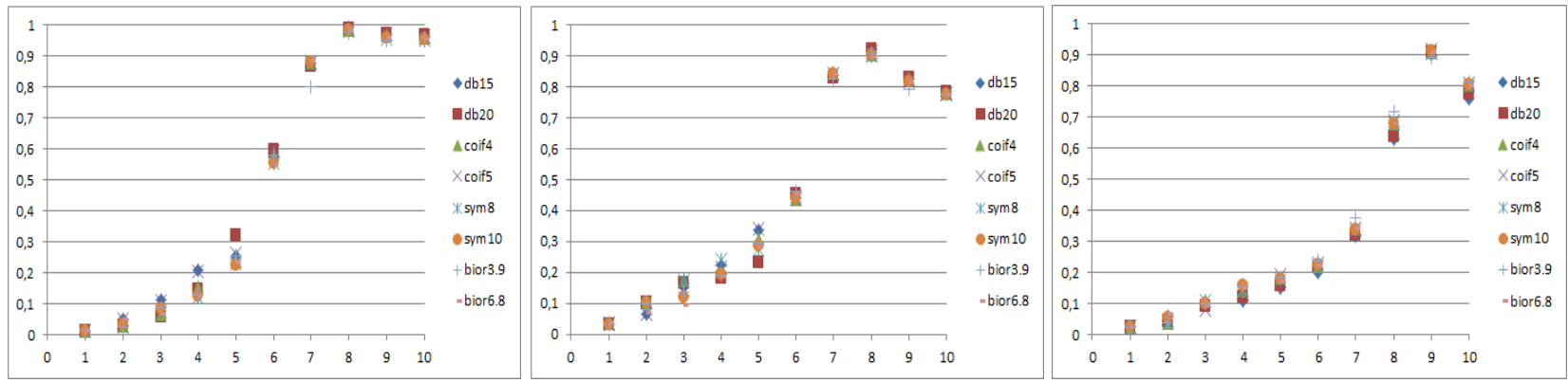

Fig. 2. Correlation coefficient values - angle of $0^{\circ}$, a) x 10 objective magnification, b) x20 objective magnification, c) $\mathrm{x} 50$ objective magnification.

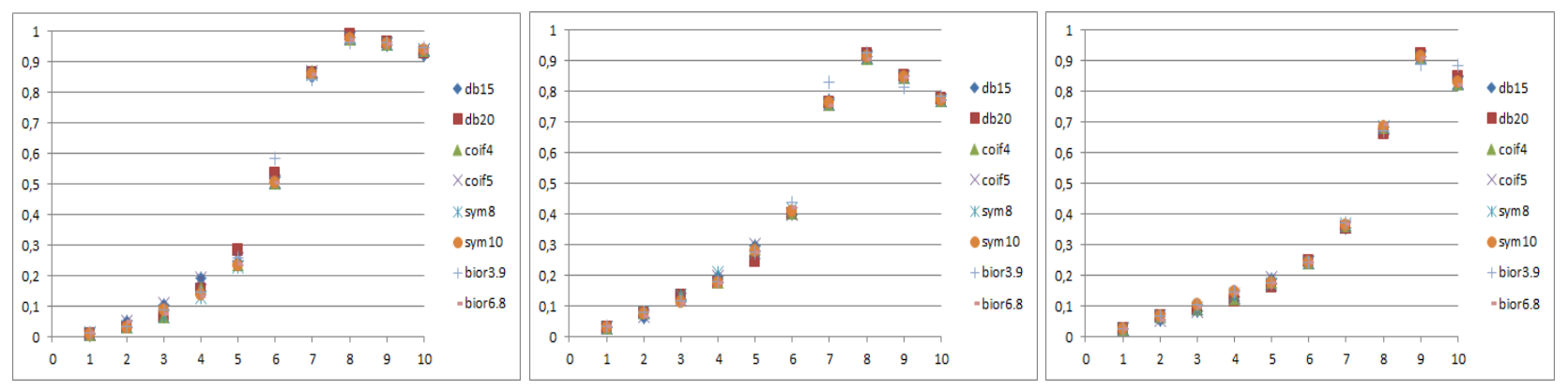

Fig. 3. Correlation coefficient values - angle of $45^{\circ}$, a) $\times 10$ objective magnification, b) x 20 objective magnification, c) x50 objective magnification. 

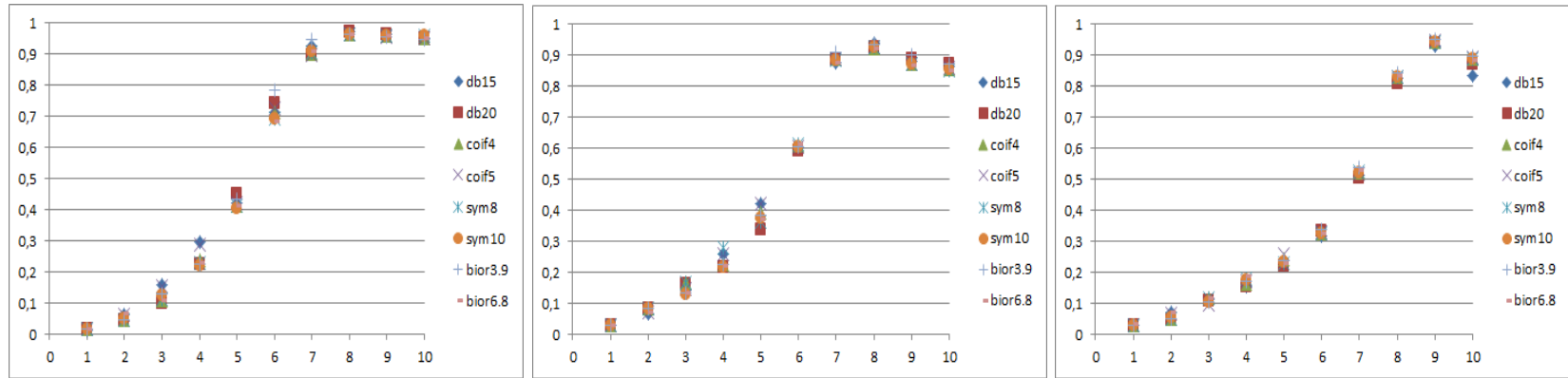

Fig. 4. Correlation coefficient values - angle of $90^{\circ}$, a) x10 objective magnification, b) x20 objective magnification, c) $\mathrm{x} 50$ objective magnification.

The values received at the initial stages of the analysis indicated no correlation between the signals, however at subsequent decomposition levels a coefficient value increases. While analyzing the received results, we should conclude that the 3D profiles created as a result of summing the signal of the details occurred in the process of discrete two-dimensional wavelet decomposition reaches the highest coefficient of correlation with the signal occurring after filtering with use of a Gaussian filter at the eighth (x10 and x20) or the ninth (x50) level, depending on an objective being used. At the next level of wavelet decomposition smaller correlation coefficient values for signals were obtained.

On the basis of the received results it should be concluded that horizontal sampling density is a key issue for the wavelet filtering process. At each analysis level it was obtained the matrix of coefficients, which size is differ than the matrix for original signal. Application of the high-pass and the low-pass filters and decrease the number of the coefficient by so called downsampling resulted in obtaining the highest correlation coefficient value at other analysis levels, depending on a matrix size. The ninth level was selected for the x50 objective magnification and the eighth level for the $\mathrm{x} 20$ objective magnification. While analyzing the matrix size, it should be mentioned that the matrix obtained for the $x 50$ zoom objective is more than two times larger, in particular rows and columns, than the matrix obtained for the measurement using the $\mathrm{x} 20$ objective magnification. Moreover, while analyzing the matrix size obtained for the $\mathrm{x} 10$ objective magnification, it can be concluded that the number of coefficients in certain rows and columns is almost two times smaller than for the $\mathrm{x} 20$ objective magnification. For these two objectives the same level of decomposition was determined, so it can concluded that analogical results shall be obtained to certain range of horizontal sampling density.

The analysis of values of the selected 3D roughness parameters was performed in order to perform the more complex analysis of the impact of wavelet transformation parameters on the process of wavelet decomposition regarding its use to divide the measured surface texture into components with various frequencies. Thus, parameter values for the signal created as a result of summing detail coefficients were determined for the selected level of wavelet decomposition. The coefficient of variation was calculated for the selected parameters in order to investigate whether there is the significant impact of the mother wavelet on the process of wavelet decomposition. The table 2 and 3 shows the collected results of the analysis.

\begin{tabular}{|c|c|c|c|c|c|c|c|c|c|c|c|}
\hline & \multirow{2}{*}{$\begin{array}{c}\text { type of } \\
\text { objective }\end{array}$} & \multirow{2}{*}{ angle, ${ }^{\circ}$} & \multicolumn{8}{|c|}{ mother wavelet } & \multirow{2}{*}{$\begin{array}{l}\text { coefficient of } \\
\text { variation, } \%\end{array}$} \\
\hline & & & db15 & db20 & coif4 & coif5 & sym8 & sym10 & bior3.9 & bior6.8 & \\
\hline \multirow{9}{*}{$\begin{array}{l}\mathrm{Sa}, \\
\mu \mathrm{m}\end{array}$} & \multirow{3}{*}{$\mathrm{x} 10$} & 0 & 9.45 & 9.38 & 9.43 & 9.41 & 9.50 & 9.45 & 9.40 & 9.48 & 0.41 \\
\hline & & 45 & 6.80 & 6.86 & 6.85 & 6.85 & 6.88 & 6.85 & 7.45 & 6.83 & 3.12 \\
\hline & & 90 & 5.03 & 5.03 & 5.09 & 5.09 & 5.08 & 5.06 & 4.98 & 5.07 & 0.75 \\
\hline & \multirow{3}{*}{$\mathrm{x} 20$} & 0 & 7.66 & 7.57 & 7.76 & 7.69 & 7.87 & 7.81 & 7.48 & 7.93 & 1.97 \\
\hline & & 45 & 5.85 & 5.79 & 5.91 & 5.87 & 5.93 & 5.91 & 5.60 & 5.97 & 1.98 \\
\hline & & 90 & 4.57 & 4.59 & 4.61 & 4.60 & 4.61 & 4.61 & 4.64 & 4.62 & 0.46 \\
\hline & \multirow{3}{*}{$\mathrm{x} 50$} & 0 & 7.38 & 7.38 & 7.60 & 7.49 & 7.67 & 7.54 & 6.80 & 7.67 & 3.77 \\
\hline & & 45 & 5.43 & 5.38 & 5.50 & 5.47 & 5.49 & 5.49 & 5.16 & 5.53 & 2.15 \\
\hline & & 90 & 4.42 & 4.38 & 4.40 & 4.37 & 4.41 & 4.40 & 4.31 & 4.44 & 0.88 \\
\hline \multirow{9}{*}{$\begin{array}{l}\mathrm{Sq}, \\
\mu \mathrm{m}\end{array}$} & \multirow{3}{*}{$\mathrm{x} 10$} & 0 & 12.56 & 12.51 & 12.56 & 12.53 & 12.69 & 12.64 & 12.84 & 12.67 & 0.86 \\
\hline & & 45 & 8.79 & 8.86 & 8.85 & 8.85 & 8.87 & 8.83 & 9.46 & 8.82 & 2.50 \\
\hline & & 90 & 6.34 & 6.33 & 6.42 & 6.42 & 6.43 & 6.40 & 6.28 & 6.40 & 0.83 \\
\hline & \multirow{3}{*}{$\mathrm{x} 20$} & 0 & 10.01 & 9.99 & 10.22 & 10.14 & 10.33 & 10.24 & 9.79 & 10.38 & 1.95 \\
\hline & & 45 & 7.29 & 7.25 & 7.44 & 7.39 & 7.46 & 7.41 & 7.00 & 7.49 & 2.19 \\
\hline & & 90 & 5.80 & 5.80 & 5.84 & 5.82 & 5.85 & 5.84 & 5.85 & 5.87 & 0.39 \\
\hline & \multirow{3}{*}{ x50 } & 0 & 9.64 & 9.62 & 9.96 & 9.81 & 10.05 & 9.90 & 8.66 & 10.08 & 4.72 \\
\hline & & 45 & 6.94 & 6.85 & 7.02 & 6.97 & 7.02 & 7.00 & 6.59 & 7.08 & 2.24 \\
\hline & & 90 & 5.63 & 5.56 & 5.56 & 5.53 & 5.57 & 5.56 & 5.48 & 5.60 & 0.78 \\
\hline
\end{tabular}

Table 2. Values of coefficient of variation 


\begin{tabular}{|c|c|c|c|c|c|c|c|c|c|c|c|}
\hline & \multirow{2}{*}{$\begin{array}{c}\text { type of } \\
\text { objective }\end{array}$} & \multirow{2}{*}{ angle, ${ }^{\circ}$} & \multicolumn{8}{|c|}{ mother wavelet } & \multirow{2}{*}{$\begin{array}{l}\text { coefficient of } \\
\text { variation, \% }\end{array}$} \\
\hline & & & db15 & db20 & coif4 & coif5 & sym8 & sym10 & bior3.9 & bior6.8 & \\
\hline \multirow{9}{*}{ Sku } & \multirow{3}{*}{$\mathrm{x} 10$} & 0 & 4.95 & 4.99 & 4.99 & 4.97 & 5.06 & 5.07 & 5.84 & 5.05 & 5.76 \\
\hline & & 45 & 3.33 & 3.35 & 3.40 & 3.39 & 3.38 & 3.36 & 3.02 & 3.37 & 3.73 \\
\hline & & 90 & 3.15 & 3.12 & 3.18 & 3.17 & 3.22 & 3.20 & 3.11 & 3.21 & 1.25 \\
\hline & \multirow{3}{*}{$\mathrm{x} 20$} & 0 & 4.42 & 4.53 & 4.64 & 4.62 & 4.59 & 4.55 & 4.82 & 4.60 & 2.44 \\
\hline & & 45 & 2.92 & 3.04 & 3.08 & 3.09 & 3.07 & 3.02 & 2.90 & 3.03 & 2.36 \\
\hline & & 90 & 3.21 & 3.20 & 3.24 & 3.23 & 3.23 & 3.23 & 2.98 & 3.26 & 2.82 \\
\hline & \multirow{3}{*}{$\times 50$} & 0 & 3.90 & 3.88 & 4.12 & 4.09 & 4.11 & 4.15 & 3.30 & 4.20 & 7.41 \\
\hline & & 45 & 3.92 & 6.68 & 3.67 & 3.65 & 3.70 & 3.71 & 3.56 & 3.78 & 2.79 \\
\hline & & 90 & 3.27 & 3.23 & 3.16 & 3.18 & 3.15 & 3.18 & 3.26 & 3.15 & 1.52 \\
\hline
\end{tabular}

Table 3. Values of coefficient of variation

While analyzing the data collected in the above tables, it should be concluded that similar values of the selected 3D surface roughness parameters were obtained for the selected mother wavelet. On the basis of the calculated coefficient of variation it can be concluded that within the range being analyzed a mother wavelet has the minor impact on values of the selected surface roughness parameters.

\section{Conclusion}

The conducted analysis confirmed that it was possible to use a wavelet transform to filter components of surface irregularities and that particular wavelet transformation parameters had the impact on obtained results.

The test results suggest that horizontal sampling density has the impact on a level of wavelet decomposition, for which the obtained 3D profile can be treated as a surface roughness surface. The ninth level of wavelet decomposition was selected for the $\mathrm{x} 50$ objective magnification and the eighth level for the $\mathrm{x} 10$ and $\mathrm{x} 20$ objectives magnification. While analyzing a matrix size, it should be noted that the number of measuring points in certain rows and columns of the matrix obtained for the $\mathrm{x} 50$ zoom objective is more than two times larger than the number of measuring points obtained as a result of measurements with use of the $\mathrm{x} 20$ objective magnification. Moreover, while analyzing the matrix size obtained for the $\mathrm{x} 10$ objective magnification, it should be concluded that the number of coefficients defining the matrix is almost two times smaller in certain rows and columns than in case for the x 20 objective magnification. The same level of decomposition was selected for these two objectives, so we can conclude that analogical results shall be obtained to some range of horizontal sampling density.

The analysis of the impact of a mother wavelet on values of the selected 3D roughness parameters proved that a type of wavelet function had only the minor impact on changes in a 3D surface roughness. The application of an alternative method of filtration which is based on wavelet transform may be adopted mainly for analysing three-dimensional surface signals, for which it is troublesome, or even in some cases impossible, to perform an analysis utilizing Gaussian filters. It is crucial to assess the particular wavelet transform parameters regarding its use in $3 \mathrm{~d}$ surface filtering, due to nowadays there are no any standards in which the methodology of application wavelet transform is described. Future research will be concern to determine the complex methodology of application this method to divide components of surface texture, taking into account method limitations related to the measurement method, number of measuring points to be analyzed, the downsampling process and properties of particular mother wavelet.

\section{Acknowledgments}

The paper has been elaborated within the framework of the research project entitled "Theoretical and experimental problems of integrated 3D measurements of elements' surfaces”, reg. no.: 2015/19/B/ST8/02643, ID: 317012, financed by National Science Centre, Poland.

\section{References}

[1] Jakubiec, W. \& Malinowski, J. (2004) Metrology of geometrical quantities, WNT, ISBN 978-83-204-3326-5, Warszawa

[2] Adamczak, S.; Stępień, K. \& Zmarzły, P. (2017) An analysis of strategies of measurement of 3d rotary elements, Proceedings of the 28th DAAAM International Symposium, pp.1096-1100, B. Katalinic (Ed.), Published by DAAAM International, ISBN 978-3-902734-11-2, ISSN 1726-9679, Vienna, Austria

[3] Suarez Castrillon, S. A; Barreiro, J.; Alegre, E.; Garcia Ordas, M. T. \& Garcia - Olalla, O. (2011) Material surface characterization using laws descriptors, Annals of DAAAM for 2011 \& Proceedings of the 22nd International DAAAM Symposium, Volume 22, No. 1, ISSN 1726-9679 ISBN 978-3-901509-83-4, Editor B. Katalinic, Published by DAAAM International, Vienna, Austria, EU, 2011 
[4] Jiang, X.; Scott, P. \& Whitehouse, D. (2008) Wavelet and their applications for surface metrology, CIRP Annals Manufacturing Technology, Vol. 57 pp. 555- 558

[5] Zou, Y.; Li, Y.; Kaestner, M. \& Reithmeier E. (2016) Low-coherence interferometry based roughness measurement on turbine blade surface using wavelet analysis, Optic and Laser in Engineering Vol. 82 pp. 113-121

[6] Jiang, X. \& Blunt, L. (2014) Third generation wavelet for the extraction of morphological features from micro and nano scalar surface, Wear, Vol. 257 pp. 1235-1240

[7] Chen, M.; Pang, Q.; Wang, J. \& Cheng, K. (2008) Analysis of 3D microtopography in machined KDP crystal surfaces based on fractal and wavelet methods, International Journal of Machine Tools and Manufacture, Vol. 48 pp. 905-913

[8] Dutta, S.; Pal, S.K. \& Sen, R. (2016) Progressive tool flank wear monitoring by applying discrete wavelet transform on turned surface images, Measurement Vol. 77 pp. 388-401

[9] Josso, B.; Burton, D.R. \& Lalor, M.J. (2012) Frequency normalized wavelet transform for surface roughness analysis and characterization, Wear, Vol. 252 pp. 491-500

[10] Lingadurai, K. \& Shunmugan, M.S. (2006) Metrological characteristics of wavelet filter used for engineering surfaces, Measurement Vol. 39 pp. 575-584

[11] Zahouani, H.; Mezghani, S.; Vargiolu, R. \& Dursapt, M. (2008) Identification of manufacturing signature by 2D wavelet decomposition, Wear, Vol. 264 pp. 480-485

[12] Yang, C.; Liu, P.; Yin, G.; Jiang, H. \& Li, X. (2016) Defect detection in magnetic title images based on stationary wavelet transform, NDT\&E International Vol. 83 pp.78-87

[13] Blateyron, F. (2014) Good practices for the use of areal filters, Proceedings of. 3rd Seminar on surface metrology of the Americas, Albuquerque.

[14] Wang, X.; Shi, T.; Liao, G.; Zhang, Y.; Hong, Y. \& Chen. K. (2017) Using wavelet packet transform for surface roughness evaluation and texture extraction, Sensors Vol 17 No. 933; DOI:10.3390/s17040933

[15] Stępień, K. \& Makieła, W (2013) An analysis of deviations of cylindrical surfaces with the use of wavelet transform, Metrology and Measurement Systems Vol. 20, No, 1 pp.139-150

[16] Gogolewski, D. \& Makieła, W. (2018). Evaluation of the impact of the horizontal sampling density on the wavelet analysis process, unpublished 